Brazilian Journal

of Chemical

Engineering

\title{
FORMULATION AND CHARACTERIZATION OF ULTRASOUND-ASSISTED NANOEMULSIONS CONTAINING PALM OIL (Elaeis guineensis Jacq) IN WATER
}

\author{
Valéria Dal Prá ${ }^{1}$, Fernanda B. Pires ${ }^{2}$, Carolina B. Dolwitsch ${ }^{2}$, Ayres P. Lazzaretti Jr. ${ }^{2}$, \\ Isabel Roggia ${ }^{3}$, Sérgio R. Mortari ${ }^{3}$, Denise M. G. Freire ${ }^{4}$, Homero Souza ${ }^{5}$, \\ Marcio A. Mazutti ${ }^{1 *}$ and Marcelo B. da Rosa ${ }^{2}$ \\ ${ }^{1}$ Universidade Federal de Santa Maria, Departamento de Engenharia Química, Santa Maria, RS, Brasil. E-mail: marciomazutti@gmail.com - \\ ORCID: 0000-0001-8217-5629 \\ ${ }^{2}$ Universidade Federal de Santa Maria, Departamento de Química, Santa Maria, RS, Brasil. \\ ${ }^{3}$ Universidade Franciscana, Ciências Tecnológicas, Santa Maria, RS, Brasil. \\ ${ }^{4}$ Universidade Federal do Rio de Janeiro, Centro de Tecnologia, Instituto de Química, Rio de Janeiro, RJ, Brasil. \\ ${ }^{5}$ Companhia Refinadora da Amazônia, Belém, PA, Brasil.
}

(Submitted: June 27, 2018 ; Revised: November 22, 2018 ; Accepted: November 23, 2018)

\begin{abstract}
This study aimed to optimize ultrasound-assisted palm oil-in-water nanoemulsions. The influence of hydrophilic-lipophilic balance (HLB), oil and surfactants concentrations, ultrasound intensity and processing time were investigated by means of two experimental designs. Desirability profiles were applied to detect the optimal conditions for preparing the nanoemulsion. Stable nanoemulsions with small droplet size and polydispersity index (PDI) were obtained at an HLB of 6.5 , oil and surfactant concentrations of $2.8 \mathrm{wt} \%$, ultrasound intensity of $200 \mathrm{~W} . \mathrm{cm}^{-2}$ and processing time of 15 minutes. The nanoemulsion presented stability for 30 days at three different temperatures $\left(4^{\circ} \mathrm{C}, 25^{\circ} \mathrm{C}\right.$ and $\left.40^{\circ} \mathrm{C}\right)$, which makes it suitable for application in the food and cosmetic industries. Ultrasound was shown to be a promising technology to produce nanoemulsions containing palm oil. Keywords: Palm oil; Nanoemulsion; Ultrasound; Formulation.
\end{abstract}

\section{INTRODUCTION}

In recent years, there is a growing interest in natural products by pharmaceutical and food industries due to an increase in the demand for natural substances instead of synthetic compounds. Many vegetable oils are recognized as good sources of functional ingredients and exhibit a great potential as raw materials in the development of natural and eco-friendly products (Badea et al., 2015; Rebolleda et al., 2015).

Palm (Elaeis guineensis Jacq) is cultivated in 42 countries. It is the most efficient oil crop with the highest yield of oil among the crops. The palm oil is a rich source of the fatty acids and other constituents such as tocopherols, tocotrienols and carotenoids (Teixeira et al., 2013; Mba et al., 2015). These compounds present high antioxidant and photoprotective activities (Dal Prá et al., 2016). However, the low stability and solubility of these compounds hampers their utilization in industry.

One alternative is the development and stabilization of an emulsion to incorporate these compounds in a formulation (Silva et al., 2015; Nikolovski et al., 2016). The incorporation of lipophilic active ingredients in an aqueous phase can be as an oil-inwater nanoemulsion, defined as nano-dispersed oil droplets in an external aqueous phase, stabilized by a surfactant system (Kiparissides and Kammona, 2012; Dias et al., 2014; Rebolleda et al., 2015; Silva et al.,

\footnotetext{
* Corresponding author: Marcio A. Mazutti - E-mail: mazutti@ufsm.br
} 
2015; Rodrígues et al., 2016; Nikolovski et al., 2016). Besides, nanoemulsions are preferable because they are colloidal systems more stable than microemulsions.

Among the methods to obtain nanoemulsions, high-intensity ultrasound is effective and has already shown promising results in the preparation of food/ pharmaceutical nanoemulsions (Kaur et al., 2016). Cavitation technology has emerged to be an energyefficient and promising technique to generate such nanoscale emulsions encapsulating a variety of highly potent pharmaceutical agents that are water-insoluble. The micro-turbulent implosions of cavitation bubbles reduce primary giant oily emulsion droplets to the nano-scale, spontaneously leading to the formation of highly uniform drug-containing nanodroplets (Sivakumar et al., 2014).

Ultrasound-assisted nanoemulsions present a lower index of polydispersity and are more stable in comparison with those from mechanical devices (Izquierdo et al., 2005; Li and Chiang 2012). Factors such as the type of oil, the energy input during emulsification and the geometry of the design of the ultrasound emulsification device affect the emulsion formed. For this reason, several ultrasonic parameters such as irradiation power, irradiation time, volume ratio of phases, surfactant concentration, viscosity, gas content, position of the ultrasonic source with respect to the liquid-liquid interface, tip diameter and vessel geometry must be properly controlled and optimized, so that the effectiveness of ultrasoundengineered nanoemulsions and their physiochemical properties can be guaranteed (Rebolleda et al., 2015; Sivakumar et al., 2014). Although some authors optimized nanoemulsions prepared by ultrasound ( $\mathrm{Li}$ and Chiang, 2012; Rebolleda et al., 2015; Alzorqui et al., 2016), there are few studies reporting its use for nanoemulsions of bioactive compounds from palm (Raviadaran et al., 2018; Parthasarathy et al., 2013).

Based on these aspects, the main objective of this study was to optimize the process variables (oil and surfactant concentrations, hydrophilic-lipophilic balance, ultrasound intensity and time of ultrasound application) to obtain stable palm oil-in-water nanoemulsions by ultrasound.

\section{MATERIALS AND METHODS}

\section{Materials}

The palm oil (Elaeis guineensis) was provided by the industry of processing of oils and derivatives Agropalma (Tailândia, PA, Brazil). Tween 80 (polyoxyethylene sorbitan monooleate) and Span 80 (sorbitan monooleate) were purchased from Sigma-Aldrich.

\section{Experimental apparatus and procedure}

The apparatus used to prepare the nanoemulsions consisted of a high intensity ultrasonic processor of
$400 \mathrm{~W}$ and frequency of $24 \mathrm{kHz}$ (Hielscher, Model UP $400 \mathrm{~S}$ ) with a titanium probe of $7 \mathrm{~mm}$ diameter and ultra-turrax (GE 700 Nurtigen-Alemanha). Palm oil and Span 80 (oil phase), as well as water and Tween 80 (aqueous phase), were homogenized separately in the ultra-turrax for 1 minute at $7000 \mathrm{rpm}$. The oil phase was mixed with the aqueous phase in the ultraturrax for 1 minute at $7000 \mathrm{rpm}$. Afterwards, the preemulsion was subjected to the high intensity ultrasonic processor at different intensities and processing times. The total mass of nanoemulsion (palm oil + water + surfactants) used was $30 \mathrm{~g}$.

The effect of process variables on the resulting characteristics of the nanoemulsions (droplet size, polydispersity index and zeta potential) was determined by means of two experimental designs. In the first one, a central composite rotational design (CCRD) was used to evaluate the effects of oil concentration $(1-10 \% \mathrm{w} / \mathrm{w})$, emulsifier concentration (1-10\% w/w) and hydrophiliclipophilic balance (HLB) (4.3-15). Ultrasound intensity and processing time were $200 \mathrm{~W} . \mathrm{cm}^{-2}$ and 10 minutes, respectively. From the results of the first CCRD, a central composite design (CCD) was conceived in order to study the effects of time (5-15 minutes) and ultrasound intensity $\left(200-400 \mathrm{~W} . \mathrm{cm}^{-2}\right)$.

At optimized conditions, the stability of palm oilin-water nanoemulsions was determined by measuring the change of droplet size, polydispersity index, zeta potential and $\mathrm{pH}$ at $0,7,15,30,60,90$ days. Three different storage conditions were evaluated: $4{ }^{\circ} \mathrm{C}, 25$ ${ }^{\circ} \mathrm{C}$ and $40{ }^{\circ} \mathrm{C}$.

\section{Nanoemulsion characterization}

The droplet size and polydispersity index (PDI) of nanoemulsions were analyzed by dynamic light scattering (DLS) using a Zetasizer Nano ZS ${ }^{\circledR}$ (Malvern Instruments Ltd. UK). The formulations were first diluted at 1:500 with ultra-pure water to obtain an adequate scattering intensity. Zeta potential (ZP) was measured with the same apparatus by using the electrophoretic light scattering technique. The formulations were now diluted 1:500 in $10 \mathrm{mM} \mathrm{NaCl}$ solution. The $\mathrm{pH}$ of the nanoemulsions was measured directly on the formulations by using a potentiometer $\left(\right.$ Digimed $\left.^{\circledR}\right)$. The PDI was a dimensionless measure of the width of the size distribution calculated from the cumulant analysis ranging from 0 to 1 .

\section{Statistical analysis}

All statistical analyses were performed using Statistica 8.0 software (Statsoft Inc., Tulsa, OK, USA), considering a 90\% significance level. Statistical differences between treatments were determined by one-way analysis of variance (ANOVA) and means were separated using the least significant difference test $(\mathrm{p}<0.10)$. 


\section{RESULTS AND DISCUSSION}

In the first step of study, the concentrations and characteristics of surfactants as well as the concentration of oil to produce nanoemulsions with high stablity were selected. Table 1 presents the results of the effect of oil and surfactant concentrations and HLB on droplet size (DS), polydispersity index (PDI) and zeta potential (ZP) of the nanoemulsions. The values ranged from $98.35 \mathrm{~nm}$ (run 5) to $346.80 \mathrm{~nm}$ (run 4) for DS, 0.186 (run 11) to 0.631 (run 14) for PDI, - $4.96 \mathrm{mV}$ (run 14) to $-28.5 \mathrm{mV}$ (run 13) for ZP, and for $\mathrm{pH} 4.80$ (run 16) to 6.14 (run 14).

Data of Table 1 were used to estimate the parameters of a quadratic model for each response. The linear, quadratic and interaction parameters can be related to the effects of each term in the response.

Table 2 presents the three models with significant terms $(p<0.1)$ as well as the ANOVA for each one of them. All models presented high values for the determination coefficient, indicating that the predictions of these models are reliable and can explain more than $77 \%$ of the experimental variation of the data. The validated models were used to make predictions to better understand the influence of process variables on responses. These predictions are presented in Fig. 1 in the form of desirability profiles.

The droplet size increased with oil concentration. There are three possible explanations for this trend (Tang et al., 2012): i) with a rise in the oil content, the droplet disruption process could be more difficult due to an increase in the viscosity of the dispersed phase, leading to an increase in the flow resistance and hence the droplet break-up rate would be severely restricted, ii) at fixed emulsifier concentration, it is possible that there is an incomplete coverage of emulsifier molecules on the freshly formed oil-water interface and thus this limitation increases the average droplet size; iii) part of the effect could be attributed to the increased rates of collision frequency, particularly at lower emulsifier concentration, between the emulsion droplets, followed by an ultimate increase of coalescence frequency, subsequently leading to a higher probability of coalescence of droplets.

The increase of surfactant concentration led to an increase of the droplet size and PDI of nanoemulsion. Excessive amounts of surfactant and oil might lead to a lower diffusion rate of surfactants and result in the coalescence of emulsion droplets (Li and Chiang, 2012; Kaur et al., 2016). This result is corroborated by Alzorqui et al. (2016), who reported that the

Table 1. Matrix of the experimental results obtained in the CCRD for the nanoemulsions.

\begin{tabular}{|c|c|c|c|c|c|c|c|}
\hline Run & $\begin{array}{c}\text { Oil } \\
(\mathrm{wt} \%)\end{array}$ & $\begin{array}{c}\text { Surfactant } \\
(w t \%)\end{array}$ & $\begin{array}{c}\text { HLB } \\
(-)\end{array}$ & $\begin{array}{c}\text { DS } \\
(\mathbf{n m})\end{array}$ & $\begin{array}{c}\text { PDI } \\
(-) \\
\end{array}$ & $\begin{array}{c}\mathbf{Z P} \\
(\mathrm{mV})\end{array}$ & pH \\
\hline 1 & $(-1) 2.8$ & (-1) 2.8 & $(-1) 6.5$ & $163.37 \pm 1.32$ & $0.195 \pm 0.016$ & $-16.33 \pm 0.58$ & 5.24 \\
\hline 2 & (1) 8.2 & (-1) 2.8 & $(-1) 6.5$ & $182.70 \pm 1.21$ & $0.198 \pm 0.009$ & $-13.27 \pm 1.18$ & 5.21 \\
\hline 3 & (-1) 2.8 & (1) 8.2 & $(-1) 6.5$ & $190.37 \pm 0.35$ & $0.254 \pm 0.011$ & $-14.77 \pm 0.71$ & 5.24 \\
\hline 4 & (1) 8.2 & (1) 8.2 & $(-1) 6.5$ & $346.80 \pm 0.28$ & $0.399 \pm 0.018$ & $-14.23 \pm 0.21$ & 5.32 \\
\hline 5 & (-1) 2.8 & (-1) 2.8 & (1) 12.8 & $98.35 \pm 1.38$ & $0.401 \pm 0.003$ & $-8.93 \pm 0.75$ & 5.70 \\
\hline 6 & (1) 8.2 & (-1) 2.8 & (1) 12.8 & $136.53 \pm 1.55$ & $0.224 \pm 0.013$ & $-9.67 \pm 0.26$ & 5.74 \\
\hline 7 & $(-1) 2.8$ & (1) 8.2 & (1) 12.8 & $140.57 \pm 1.12$ & $0.526 \pm 0.004$ & $-8.92 \pm 0.61$ & 5.72 \\
\hline 8 & (1) 8.2 & (1) 8.2 & (1) 12.8 & $128.83 \pm 3.92$ & $0.321 \pm 0.045$ & $-7.18 \pm 0.48$ & 5.86 \\
\hline 9 & $(-1.68) 1$ & (0) 5.5 & (0) 9.7 & $105.20 \pm 4.95$ & $0.440 \pm 0.098$ & $-8.88 \pm 0.78$ & 5.38 \\
\hline 10 & (1.68) 10 & (0) 5.5 & (0) 9.7 & $155.01 \pm 1.40$ & $0.277 \pm 0.007$ & $-10.28 \pm 0.38$ & 5.53 \\
\hline 11 & (0) 5.5 & $(-1.68) 1$ & (0) 9.7 & $158.60 \pm 1.75$ & $0.186 \pm 0.017$ & $-9.49 \pm 0.68$ & 5.53 \\
\hline 12 & (0) 5.5 & (1.68) 10 & (0) 9.7 & $128.67 \pm 1.25$ & $0.397 \pm 0.015$ & $-8.65 \pm 0.61$ & 5.47 \\
\hline 13 & (0) 5.5 & (0) 5.5 & $(-1.68) 4.3$ & $214.10 \pm 3.98$ & $0.486 \pm 0.011$ & $-28.5 \pm 0.98$ & 4.82 \\
\hline 14 & (0) 5.5 & (0) 5.5 & (1.68) 15 & $137.30 \pm 6.08$ & $0.631 \pm 0.135$ & $-4.96 \pm 0.45$ & 6.14 \\
\hline 15 & (0) 5.5 & (0) 5.5 & (0) 9.7 & $120.50 \pm 2.23$ & $0.351 \pm 0.014$ & $-10.87 \pm 0.65$ & 5.48 \\
\hline 16 & (0) 5.5 & (0) 5.5 & (0) 9.7 & $119.57 \pm 1.60$ & $0.291 \pm 0.036$ & $-8.58 \pm 0.68$ & 4.80 \\
\hline 17 & (0) 5.5 & (0) 5.5 & (0) 9.7 & $111.70 \pm 0.91$ & $0.279 \pm 0.015$ & $-11.03 \pm 0.40$ & 5.43 \\
\hline
\end{tabular}

Table 2. Models represented in equations and ANOVA for validation.

\begin{tabular}{|c|c|c|c|c|c|c|c|}
\hline Equation & $\begin{array}{c}\text { Source } \\
\text { of variation }\end{array}$ & $\begin{array}{c}\text { Sum } \\
\text { of squares }\end{array}$ & $\begin{array}{c}\text { Degrees } \\
\text { of freedon }\end{array}$ & $\begin{array}{c}\text { Mean } \\
\text { squares }\end{array}$ & F calc & $\mathbf{F}_{\text {tab }}$ & $\mathbf{R}^{2}$ \\
\hline \multirow{6}{*}{$\begin{array}{c}\mathrm{PDI}=0.31-0.049 . \mathrm{P}+0.068 . \mathrm{P}^{2}+0.061 . \mathrm{L}-0.037 . \mathrm{O}- \\
0.066 . \mathrm{P} . \mathrm{O}\end{array}$} & Regression & 23625.32 & 2 & 11802.66 & \multirow[t]{3}{*}{5.86} & \multirow[t]{3}{*}{2.73} & \multirow[t]{3}{*}{0.7677} \\
\hline & Residual & 28172.46 & 14 & 2012.32 & & & \\
\hline & Total & 51797.78 & 16 & & & & \\
\hline & Regression & 0.2107 & 5 & 0.0421 & 10.02 & 2.45 & 0.8587 \\
\hline & Residual & 0.0463 & 11 & 0.0042 & & & \\
\hline & Total & 0.2570 & 16 & & & & \\
\hline \multirow[t]{2}{*}{$\mathrm{ZP}=10.18-4.71 . \mathrm{P}+2.25 . \mathrm{P}^{2}$} & Residual & 67.07 & 14 & 4.79 & \multirow{2}{*}{39.61} & \multirow{2}{*}{2.73} & \multirow{2}{*}{0.8667} \\
\hline & Total & 446.56 & 16 & & & & \\
\hline
\end{tabular}

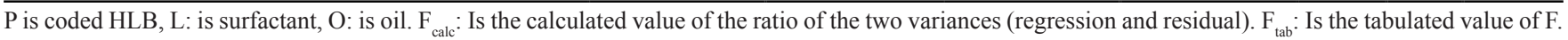


Oil
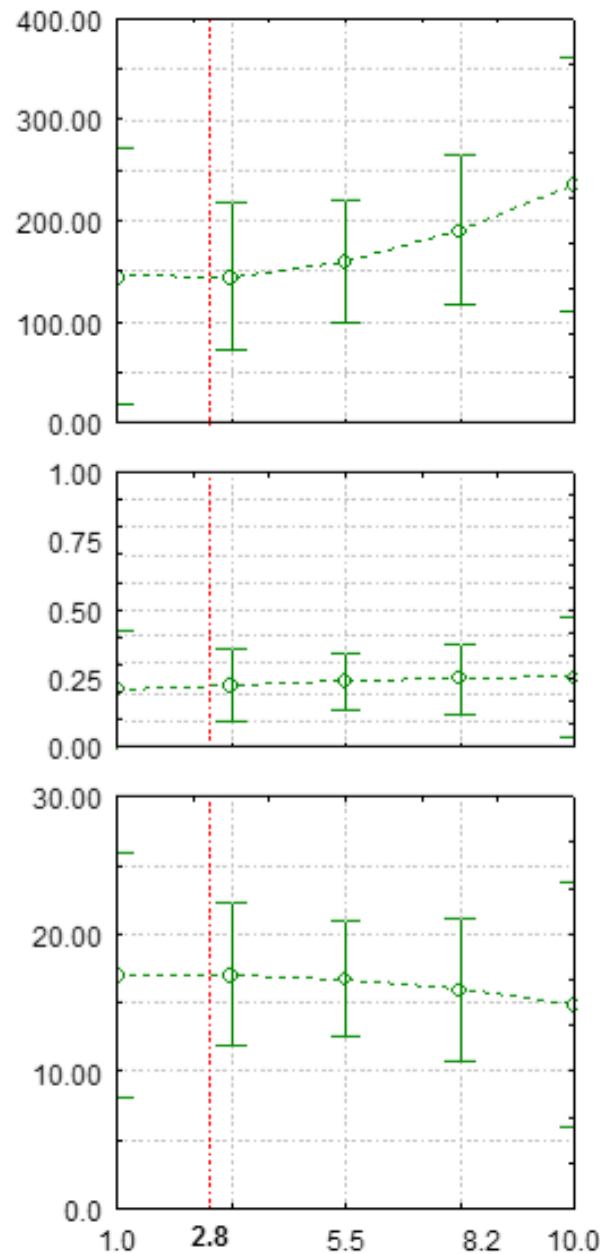
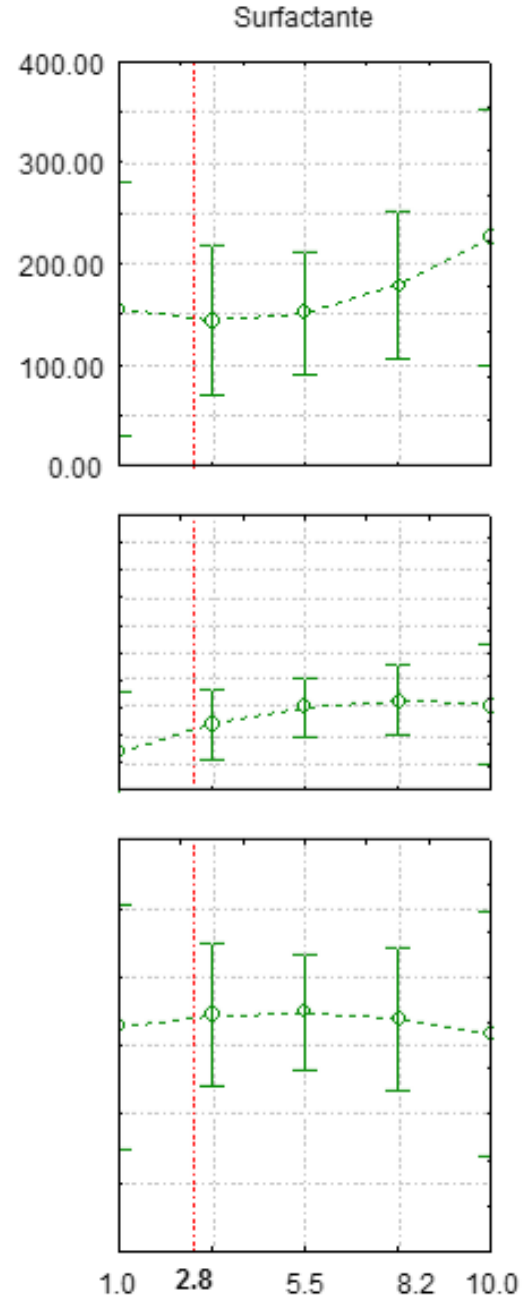

$\mathrm{HLB}$
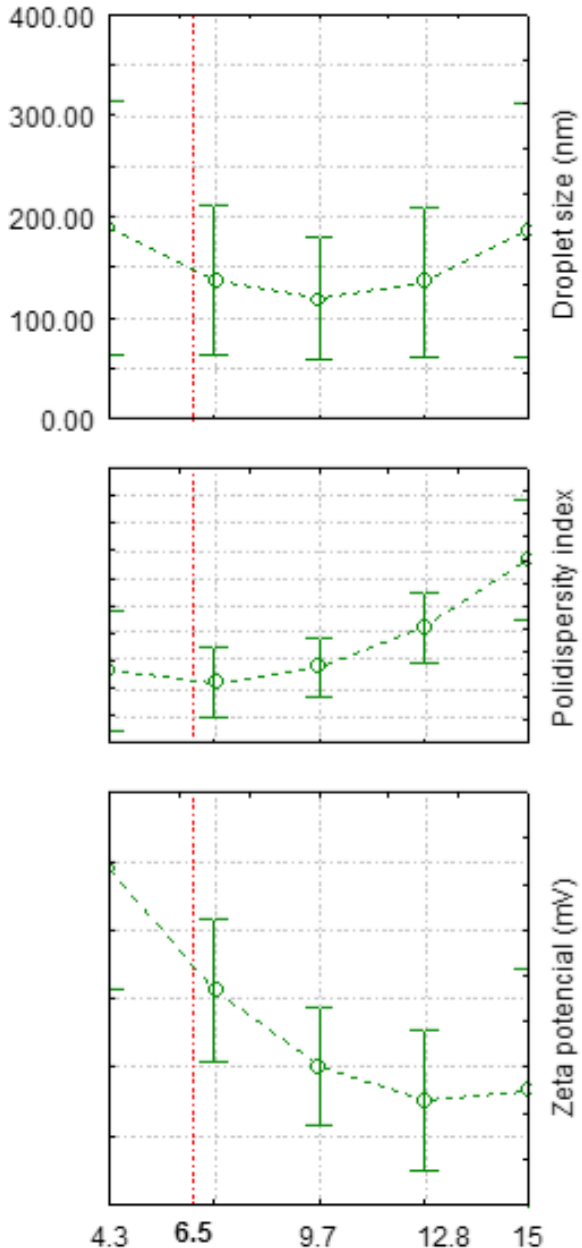

Figure 1. Desirability profiles expressing the influence of the process variables HLB, oil and surfactant concentration on the droplet size, polydispersity index and zeta potential.

excess amount of surfactant affects the diffusion rate of surfactant as well as the adsorption of surfactantdroplet and therefore leads to an increase of the coalescence of the newly disrupted-droplets. During emulsification, surfactants generally improve the disruption rate by reducing the interfacial tension and also by helping prevent coalescence of droplets. The final droplet size in the emulsion is the net effect of the rate of droplet break-up as well as coalescence, and these are mainly governed by the emulsifier surface activity and concentration (Agrawal et al., 2017; Tang et al., 2012).

Regarding the PDI increase as a function of oil and surfactant concentration, the reason for this is that the high concentration of emulsifier led to an increase in the flow resistance in the batch emulsification process, which in turn resulted in the larger magnitude of the apparent viscosity of the prepared emulsions. Subsequently, the higher emulsion viscosity caused an attenuation of ultrasonic waves propagation generated near the microtip surface and hence reduced the shear stress predominantly induced by the acoustic cavitation deemed to be responsible for the droplet disruption. Consequently, the increased viscosity resulting from the higher concentration of emulsifier could considerably affect the ultrasound-assisted emulsification efficiency, thereby promoting a higher coalescence rate, which in turn resulted in larger droplet sizes, PDI and lower ZP (Tang et al., 2012).

The ultrasound-assisted nanoemulsion formation occurs in two steps (Sivakumar et al. 2014): i) generation of primary droplets, where the acoustic field produces the interfacial waves; ii) the breakup of primary droplets where the acoustic cavitation causes localized intense turbulence and shear forces that produce violently and asymmetrically imploding bubbles and cause microjets which effectively further break the primary droplets of dispersed oil generated in the first stage into droplets of nanometric-size. Resistance of droplets to deformation is determined by the surfactant and its characteristics. In this work, the lowest values of DS and PDI and the highest value for ZP (in module) were obtained for an HLB of 6.5 and for oil and surfactant concentrations of $2.8 \mathrm{wt} \%$. At 
this condition, the concentrations of oil and surfactant favored the formation of the smallest droplet size with adequate rate of diffusion and effective adsorption of the surfactant onto the newly formed droplets.

After the selection of oil and surfactant concentrations as well as HLB, a central composite design (CCD) was used to study the effects of ultrasound time (5-15 minutes) and ultrasound intensity $\left(200-400 \mathrm{~W} . \mathrm{cm}^{-2}\right)$ on the characteristics of nanoemulsions. This is an important step in the study, because it is possible to identify the effect of ultrasonic operating parameters on the droplet break-up and coalescence, which are particularly important for obtaining smaller nano-sized emulsion droplets with narrower distribution. In ultrasound emulsification, the rate of droplet break-up is primarily controlled by cavitation-induced shear forces applied to droplets as well as the droplet resistance to deformation (Tang et al., 2012).

Table 3 presents the DS, PDI, ZP and $\mathrm{pH}$ obtained in the eighteen runs of the CCD. DS ranged from $167.43 \mathrm{~nm}$ (run 1) to $212.47 \mathrm{~nm}$ (run 8), PDI from 0.200 (run 6) to 0.358 (run 8), $\mathrm{ZP}$ from $-14.87 \mathrm{mV}$ (run 5) to $-22.0 \mathrm{mV}$ (run 2) and $\mathrm{pH}$ from 4.51 (run 5) to 5.79 (run 3). The effects of process variables are presented in Table 4.

Ultrasound intensity and time of application of ultrasound did not present significant influence $(p<0.05)$ on the responses studied (DS, PDI, ZP and $\mathrm{pH})$. In a general way, there was an optimum power level for attaining the maximum effect of acoustic emulsification. Therefore, there is no further decrease in average droplet size when the maximum dispersity at the given ultrasound intensity has been reached. According to Tang et al. (2012), at higher operating amplitude, an intense local turbulence and shear flow

Table 3. Matrix of the experimental results obtained in the CCD for nanoemulsions.

\begin{tabular}{|c|c|c|c|c|c|c|}
\hline Run & $\begin{array}{l}\text { Time } \\
(\mathbf{m i n})\end{array}$ & $\begin{array}{l}\text { Ultrasound } \\
\text { intensity } \\
\left(\mathrm{W} \mathrm{cm}^{-2}\right)\end{array}$ & $\begin{array}{c}\text { DS } \\
(\mathbf{n m})\end{array}$ & $\begin{array}{c}\text { PDI } \\
(-)\end{array}$ & $\begin{array}{c}\mathbf{Z P} \\
(\mathrm{mV})\end{array}$ & pH \\
\hline 1 & 5 & 200 & 167.43 & 0.228 & -15.70 & 5.72 \\
\hline 2 & 15 & 200 & 176.40 & 0.257 & -22.00 & 5.65 \\
\hline 3 & 5 & 400 & 212.17 & 0.371 & -18.37 & 5.79 \\
\hline 4 & 15 & 400 & 181.90 & 0.243 & -15.57 & 5.66 \\
\hline 5 & 10 & 300 & 208.93 & 0.326 & -14.87 & 4.51 \\
\hline 6 & 10 & 300 & 169.33 & 0.200 & -16.07 & 5.45 \\
\hline 7 & 10 & - & 60 & 0.203 & -16.5 & 5.32 \\
\hline 8 & 10 & 400 & 212.47 & 0.358 & -17.4 & 4.98 \\
\hline
\end{tabular}

field is generated in the vicinity of the probe microtip and this larger turbulent force promotes a higher rate of collision between droplets.

The findings that the ultrasound intensity and treatment time were not significant in the studied range of independent variables is associated with a correct selection of oil and surfactant concentrations, surfactant characteristics and ultrasonic parameters. Several authors demonstrated that these variables affect the rate of emulsifier adsorption onto the droplet surface as well as the droplet size distribution of newly formed droplets (Jena and Das, 2006; Li and Chiang et al., 2012). In this work, a stable emulsion with small droplet size and PDI was obtained at an ultrasound intensity of $200 \mathrm{~W} \cdot \mathrm{cm}^{-2}$ and processing time of 15 minutes (run 2).

After two experimental designs, the best condition for the ultrasound-assisted palm oil-in-water nanoemulsion was an HLB of 6.5, oil and surfactant concentrations of $2.8 \mathrm{wt} \%$, ultrasound intensity of 200 W.cm ${ }^{-2}$ and processing time of 15 minutes. At such conditions, the physical stability of the nanoemulsions was examined under different storage conditions (4 ${ }^{\circ} \mathrm{C}, 25^{\circ} \mathrm{C}$ and $40{ }^{\circ} \mathrm{C}$ ) by monitoring the droplet size, polydispersity index, zeta potential and $\mathrm{pH}$ for 0,7 , 15,30 days.

The stability results are shown in Fig. 2. Independent of storage temperature and time, no visible creaming or flocculation was observed. At $4^{\circ} \mathrm{C}$, the nanoemulsion exhibited good stability, without significant $(\mathrm{p}<0.05)$ changes in the droplet size and PDI. However, zeta potential presented a significant decrease in its value. At room temperature $\left(25{ }^{\circ} \mathrm{C}\right)$, the nanoemulsion presented good stability for 30 days of storage and presented behavior similar to that maintained at $4^{\circ} \mathrm{C}$. The droplet diameter increased in this period, and the zeta potential decreased. The greatest variation in the properties of the nanoemulsion was verified at $40{ }^{\circ} \mathrm{C}$. For example, there was greater variation of $\mathrm{pH}$ values, while in the other conditions the $\mathrm{pH}$ values were stable. These results are in accordance with the literature (Rebolleda et al., 2015; Alzorqui et al. 2016; Carpenter and Saharan, 2017).

The good stability of the nanoemulsion obtained in this study may be attributed to the fact that the surfactant concentrations were $6,000 \mathrm{mg} / \mathrm{L}$ and 22,000 $\mathrm{mg} / \mathrm{L}$ for Tween 80 and Span 80 , respectively. These concentrations are many times higher than the critical micellar concentration (CMC) of the surfactants (CMC

Table 4. Effect of the variables time and ultrasound intensity on droplet size, polydispersity index and zeta potential.

\begin{tabular}{cccccccccc}
\hline \multirow{2}{*}{$\begin{array}{c}\text { Source } \\
\text { of variation }\end{array}$} & Effect & $\begin{array}{c}\text { Droplet size } \\
\text { Error }\end{array}$ & p-value & Effect & $\begin{array}{c}\text { Std. } \\
\text { Error }\end{array}$ & p-value & Effect & $\begin{array}{c}\text { Std. } \\
\text { Error }\end{array}$ & p-value \\
\hline Time & -10.65 & 18.91 & 0.61 & -0.049 & 0.063 & 0.49 & 1.75 & 1.73 & 0.38 \\
UI & 25.12 & 18.91 & 0.27 & 0.064 & 0.063 & 0.38 & -1.88 & 1.73 & 0.35 \\
Time X UI & -19.62 & 18.91 & 0.37 & -0.08 & 0.063 & 0.30 & -4.55 & 1.73 & 0.08 \\
\hline
\end{tabular}



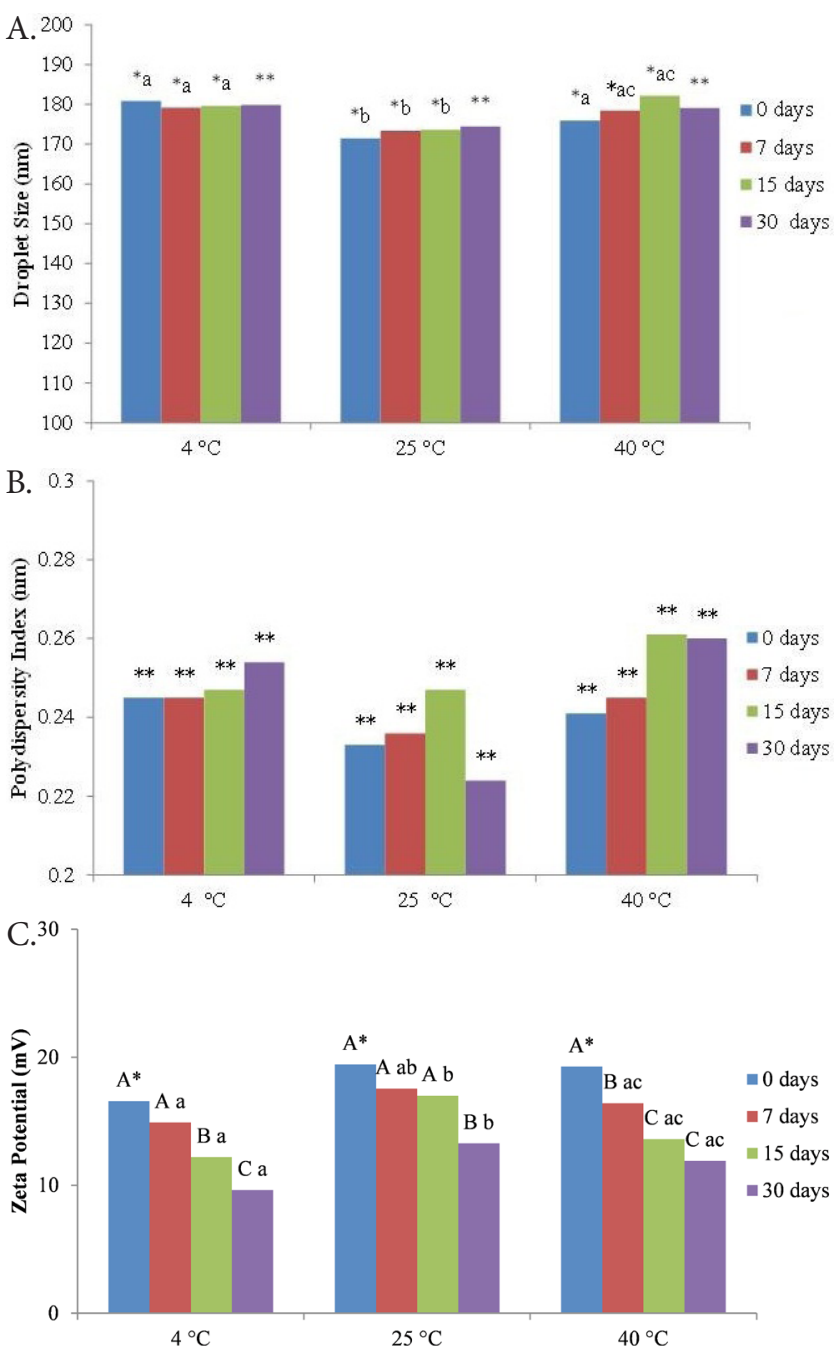

Figure 2. Bar graph expressing the physical stability of the nanoemulsion examined under different storage conditions $\left(4{ }^{\circ} \mathrm{C}, 25^{\circ} \mathrm{C}\right.$ and $40^{\circ} \mathrm{C}$ ) by monitoring the droplet size (a), polydispersity index (b), and zeta potential (c) for $0,7,15,30$ days.

Tween: 13-15 mg/liter, CMC Span: 8 mg/L). Micelles are obtained only for surfactant concentrations above the CMC and are thermodynamically more stable.

\section{CONCLUSIONS}

Two experimental designs were conceived to evaluate the influence of process variables on the ultrasound-assisted palm oil-in-water nanoemulsions. Stable nanoemulsions with small droplet size and PDI were obtained at an HLB of 6.5 , oil and surfactant concentrations of $2.8 \mathrm{wt}^{\mathrm{m}} \mathrm{\text {, }}$, ultrasound intensity of $200 \mathrm{~W} . \mathrm{cm}^{-2}$ and processing time of 15 minutes. The nanoemulsion presented stability for 30 days at three different temperatures $\left(4^{\circ} \mathrm{C}, 25^{\circ} \mathrm{C}\right.$ and $\left.40^{\circ} \mathrm{C}\right)$, which makes it suitable for use in food and cosmetic applications. Ultrasound was shown to be a promising technology to produce nanoemulsions containing palm oil.

\section{ACKNOWLEDGMENTS}

The authors thank the CNPq (Conselho Nacional de Desenvolvimento Científico e Tecnológico) for the financial support of this work and scholarships.

\section{REFERENCES}

Agrawal, N., Maddikeri, G.L., Pandit, A. Sustained release formulations of citronella oil nanoemulsion using cavitational techniques. Ultrasonics Sonochemistry, 36, 367-374 (2017). https://doi. org/10.1016/j.ultsonch.2016.11.037

Alzorqi, I., Ketabchi, M. R., Sudheer, S., Manickam, S. Optimization of ultrasound induced emulsification on the formulation of palm-olein based nanoemulsions for the incorporation of antioxidant $\beta$-D-glucan polysaccharides. Ultrasonics Sonochemistry, 31, 71-84 (2016). https://doi.org/10.1016/j.ultsonch.2015.12.004

Badea, G., Lacatasu, I., Badea, N., Ott, C., Meghea, A. Use of various vegetable oils in designing photoprotective nanostructured formulations for UV protection and antioxidant activity. Industrial Crops and Products, 67, 18-24 (2015). https://doi. org/10.1016/j.indcrop.2014.12.049

Carpenter, J., Saharan, V.K. Ultrasonic assisted formation and stability of mustard oil in water nanoemulsion: Effect of process parameters and their optimization. Ultrasonics Sonochemistry, 35, 422-430 (2017). https://doi.org/10.1016/j. ultsonch.2016.10.021

Dal Prá, V., Soares, J. F., Monego, D. L., Vendruscolo, R. G., Freire, D. M. G., Alexandri, M., Koutinas, A., Wagner, R., Mazutti, M. A., da Rosa, M. B. Extraction of bioactive compounds from palm (Elaeis guineensis) pressed fiber using different compressed fluids. The Journal of Supercritical Fluids, 112, 51-56 (2016). https://doi.org/10.1016/j. supflu.2016.02.011

Dias, D.O., Colombo, M., Kelmann, R. G., Kaiser, S., Lucca, L. G., Teixeira, H. F., Limberger, R. P. Optimization of Copaiba oil-based nanoemulsions obtained by different preparation methods. Industrial Crops and Products, 59, 154-162 (2014). https://doi.org/10.1016/j.indcrop.2014.05.007

Izquierdo, P., Feng, J., Esquena, J., Tadros, T. F., Dederen, J. C., Garcia, M. J., Azemar, N., Solans, C. The influence of surfactant mixing ratio on nanoemulsion formation by the pit method. Journal of Colloid and Interface Science, 285, 388-394 (2005). https://doi.org/10.1016/j.jcis.2004.10.047

Jena, S., Das, H. Modeling of particle size distribution of sonicated coconut milk emulsion: effect of emulsifiers and sonication time. Food Research International, 39, 606-611 (2006). https://doi. org/10.1016/j.foodres.2005.12.005 
Kaur, K., Kumar, R., Mehta, S. K. Formulation of saponin stabilized nanoemulsion by ultrasonic method and its role to protect the degradation of quercetin from UV light. Ultrasonics Sonochemistry, 31, 29-38 (2016). https://doi. org/10.1016/j.ultsonch.2015.11.017

Kiparissides, C., Kammona, O., Nanoscale carriers for targeted delivery of drugs and therapeutic biomolecules. The Canadian Journal of Chemical Engineering, 91, 638-651 (2012). https://doi. org/10.1002/cjce. 21685

Li, P.H., Chiang, B.H. Process optimization and stability of D-limonene-in water nanoemulsions prepared by ultrasonic emulsification using response surface methodology. Ultrasonics Sonochemistry, 19, 192-197 (2012). https://doi. org/10.1016/j.ultsonch.2011.05.017

Mba, O.I., Dumont, M.J., Ngadi, M. Palm oil: Processing, characterization and utilization in the food industry-A review. Food Bioscience, 10, 26-41 (2015). https://doi.org/10.1016/j.fbio.2015.01.003

Moraes, S.L., Rezende, M.O.O. Determination of the critical micelle concentration of humic acids by spectroscopy and conductimetric measurements. Química Nova, 27, 701-705 (2004). https://doi. org/10.1590/S0100-40422004000500004

Nikolovski, B.G., Ili'c, J.D., Sovilj, M.N. How to formulate a stable and monodisperse water-in-oil nanoemulsion containing pumpkin seed oil: the use of multiobjective optimization. Brazilian Journal of Chemical Engineering, 33, 919-931 (2016). https:// doi.org/10.1590/0104-6632.20160334s20140140

Parthasarathy, S., Ying, T.S., Sivakumar, M. Generation and Optimization of Palm Oil-Based Oil-in-Water $(\mathrm{O} / \mathrm{W})$ Submicron-Emulsions and Encapsulation of Curcumin Using a Liquid Whistle Hydrodynamic Cavitation Reactor (LWHCR). Industrial \& Engineering Chemistry Research, 52, 11829-11837 (2013). https://doi.org/10.1021/ie4008858
Raviadaran, R., Chandran, D., Shin, L.H., Sivakumar, M., Optimization of palm oil in water nanoemulsion with curcumin using microfluidizer and response surface methodology. LWT - Food Science and Technology, 96, 58-65 (2018). https:// doi.org/10.1016/j.lwt.2018.05.022

Rebolleda, S., Sanz, M.T., Benito, J.M., Beltrán, S., Escudero, I., San-José, M.L.G. Formulation and characterization of wheat bran oil-in-water nanoemulsions. Food Chemistry, 167, 16-23 (2015). https://doi.org/10.1016/j.foodchem.2014.06.097

Rodríguez, J., Martín, M.J., Ruiz, M.A., Clares, B. Current encapsulation strategies for bioactive oils: From alimentary to pharmaceutical perspectives. Food Research International , 83, 41-59 (2016). https://doi.org/10.1016/j.foodres.2016.01.032

Silva, E. K., Gomes, M.T.M.S., Hubinger, M.D., Cunha, R. L., Meireles, M. A. A. Ultrasound-assisted formation of annatto seed oil emulsions stabilized by biopolymers. Food Hydrocolloids, 47, 1-13 (2015). https://doi.org/10.1016/j.foodhyd.2015.01.001

Sivakumar, M., Tang, S.Y., Tan, K.W. Cavitation technology - A greener processing technique for the generation of pharmaceutical nanoemulsions. Ultrasonics Sonochemistry, 21, 2069-2083 (2014). https://doi.org/10.1016/j.ultsonch.2014.03.025

Tang, S.Y., Manickam, S., Wei, T.K., Nashiru, B. Formulation development and optimization of a novel Cremophore EL-based nanoemulsion using ultrasound cavitation. Ultrasonics Sonochemistry, 19, 330-345 (2012). https://doi.org/10.1016/j. ultsonch.2011.07.001

Teixeira, C.B., Macedo, G.A., Macedo, J.A., Silva, L.H. da, Rodrigues, A.M. Simultaneous extraction of oil and antioxidant compounds from oil palm fruit (Elaeis guineensis) by an aqueous enzymatic process. Bioresource Technology, 129, 575-581 (2013). https://doi.org/10.1016/j. biortech.2012.11.057 
